\title{
ESCALAS DA DESIGUALDADE URBANA: a Cidade do Rio de Janeiro e as Favelas
}

Camila Lima e Silva de Carvalho ${ }^{1}$

RESUMO

No Brasil, o senso comum aponta as favelas como o lugar urbano da pobreza, da violência e marginalidade, por excelência. 0 objetivo deste trabalho é mostrar que essa descrição das favelas como bolsões de pobreza só é pertinente numa determinada estratégia de agregação espacial dos dados censitários - ou seja, uma certa escala geográfica. Quando a análise é feita considerando os limites de uma favela individual, o que emerge é um mosaico de faixas de renda, a exemplo do observado na escala da cidade. A hipótese deste trabalho é de que as favelas possuem uma estrutura socioespacial análoga à da cidade, caracterizando-as como uma espécie de "cidades dentro da cidade". Utilizando dados do Censo, agregados ao nível do setor censitário, calculamos o Índice de Moran para a variável renda e, uma vez identificados os clusters de alta e baixa renda, analisamos os dados socioeconômicos e de infraestrutura, relativos a 2010. Estudamos os três maiores agrupamentos de favelas no Rio de Janeiro: Rocinha, Complexo do Alemão e Fazenda Coqueiro. Os resultados indicaram que as favelas têm reproduzido a desigualdade observada na escala da cidade. Articuladas à estrutura urbana mais ampla, as favelas se comportam como fractais, na medida em que também reproduzem esta estrutura.

PALAVRAS-CHAVE: Desigualdade; Favela; Escalas; Fractal.

\section{ABSTRACT}

In Brazil, common sense recognizes the favelas as the urban places of poverty, violence and marginality par excellence. This paper aims to show that such a description is only pertinent in a specific strategy of spatial aggregation of the census data - i.e., a geographic scale. When one analyses the data considering the boundaries of a single favela, what emerges is a mosaic of income levels, just as observed at the city scale. This work hypothesizes that individual favelas have a socio-spatial structure analogous to that of the city, what makes each one of them a kind of "cities within the city." Using census-tract level data, we calculated the Moran Index for the income variable and, once having identified the high and low-income clusters, we analyzed social and infrastructure data referenced to 2010. We studied the three biggest favelas in Rio de Janeiro: Rocinha, Complexo do Alemão and Fazenda Coqueiro. The results indicate that the favelas reproduce the inequality observed in the city at large. Articulated to the wider urban structure, favelas behave like fractals, insofar as they also reproduce this structure.

KEY-WORDS: Inequality; Slum; Scales; Fractal.

\section{Introdução}

No Rio de Janeiro, o senso comum aponta as favelas como o lugar da pobreza, da violência e marginalidade, por excelência. Segundo pesquisa recente do Instituto Data Popular, que buscou mostrar a visão da população em relação às favelas, nota-se que o preconceito ainda é muito grande. Por exemplo, a pesquisa que consultou 3.050 pessoas em 150 cidades do país realizada em janeiro de 2015, aponta que $69 \%$ dos entrevistados disseram que têm

1 Doutoranda em Arquitetura e Urbanismo pela Universidade Federal Fluminense, Professora do Centro Universitário Redentor. Contato: lsc.camila@gmail.com 
medo quando passam em frente a uma favela e $51 \%$ afirmaram que as primeiras palavras que lhes vêm à mente quando ouvem falar de favela são droga e violência ${ }^{2}$.

Silva (2012, p.248) argumenta que é preciso reconhecer que a categoria favela foi construída socialmente como um lugar homogêneo da pobreza, da marginalidade e da desorganização social. Embora modificada ao longo das décadas, ainda hoje a forma hegemônica de percepção das favelas é constituída por certas imagens como, por exemplo,

(...) a sua associação com a pobreza econômica; a falta de formação escolar; a predominância do trabalho manual; o fenótipo dos moradores - em sua maioria - pretos ou pardos; a precariedade das moradias, dos serviços e equipamentos urbanos; a origem nordestina, região considerada 'problema' no país, a ocupação ilegal de terras; a falta de pagamento de taxas e impostos diversos etc.

Os dados de renda do Censo Demográfico do Instituto Brasileiro de Geografia e Estatística (IBGE) podem fortalecer essa visão. A descrição das favelas como bolsões de pobreza encontra a sua pertinência numa determinada estratégia de agregação e dimensionamento espacial dos dados - ou seja, uma certa escala geográfica. Quando os dados são analisados na escala da cidade, as favelas realmente se apresentam como áreas de menor renda. Mas isso não significa que o espaço interno das favelas seja homogeneamente pobre. Quando restringimos a abrangência da análise aos limites de uma favela individual, o que emerge é um mosaico de faixas de renda análogo ao mosaico observado na escala da cidade.

Conforme apontam Preteicelle e Valladares (2000, p. 482-3), "os pobres que residem nas favelas não são todos iguais, revelando a presença de desigualdades dentro da pobreza". Machado da Silva (2011) vai além ao afirmar que a favela não pode ser considerada um estrato social homogêneo. Este autor cunha o termo "burguesia favelada" para se referir a um grupo de moradores da favela que tem um poder político e, muitas vezes, econômico sobre o lugar.

A partir do reconhecimento destas desigualdades, cabe a questão: Seriam essas desigualdades apenas "sociais"? Não teriam elas também uma estrutura "espacial"? Uma resposta positiva a essa pergunta implicaria na remodelação da imagem geográfica da favela: ela não seria mais vista como um lugar homogeneamente pobre, mas como um mosaico de áreas sociais que - embora resultante de dinâmicas não exatamente iguais àquelas que atuam na escala da cidade como um todo - a caracterizaria como uma espécie de "cidade dentro da cidade" (Carvalho, 2016).

Em outras palavras, a hipótese geral deste trabalho é de que as favelas são espaços internamente diferenciados em termos socioeconômicos e que essa diferenciação é análoga àquela que estrutura a cidade como um todo. Argumenta-se, portanto, que as favelas não podem ser representadas como um lugar homogêneo. Sobretudo as favelas maiores e os "complexos" de favelas são verdadeiros espaços geográficos, mosaicos de condições e níveis de vida diferenciados. Como bem expressa um dos termos em inglês (shantytowns), as favelas são como vilas ou pequenas cidades, ou pelo menos possuem uma complexidade socioespacial comparável a elas.

Usando dados da década de 1960, Morris (1973, p.31) já apontava a diferenciação socioespacial das favelas:

Existe clara e nítida distinção social dentro da favela, baseada às vezes no estado de origem dos moradores, (nordestinos ou mineiros, etc.), mas na maioria dos casos na situação econômica dos grupos. A classe comercial da

216 de fev. de 2015. Disponível em <http://www.cartacapital.com.br/sociedade/moradores-do-asfalto-temvisao-preconceituosa-em-relacao-a-favelas-4298.html?utm_content=buffer90 5f2\&utm_medium=social\&utm _ source=twitter.com\&utm_campaign=buffer $>$ Acesso em 24 fev. 2015. 
favela (os comerciantes, proprietários etc.) e suas famílias, que normalmente poderiam viver em outro lugar se quisessem, geralmente ocupam a camada mais elevada da sociedade da favela, em contraposição ao grupo maior que não tem escolha.

As favelas são diferentes entre si e em si mesmas, por diversos fatores. Além de diferentes entre si, uma favela possui diferenciações dentro de seu próprio território que podem ser de ordens diversas. Os estudiosos das favelas reconhecem essas diferenciações, apontando que "as favelas apresentam sinais evidentes de heterogeneidade - em sua realidade física, espacial e social" (Valladares, 2005, p. 157). Nunes (2007, p.9) complementa afirmando que "representá-las como um tecido homogêneo e uniforme pode significar um grande reducionismo". Alvito (2001, p. 61), em sua etnografia sobre a favela de Acari, reconhece ainda dentro de cada localidade "dezenas de microáreas de vizinhanças", as quais "servem de base para representação acerca das diferenças existentes dentro de uma única favela". Essas colocações apontam para a necessidade de se recorrer a outras escalas para a apreensão da complexidade interna às favelas e da própria estruturação urbana.

Estudos como estes têm se baseado geralmente em observação qualitativa. Como contribuição ao tema da desigualdade intra-favela, o objetivo deste trabalho é estudar a desigualdade socioespacial interna às favelas cariocas por meio de análise espacial quantitativa, usando dados censitários agregados ao nível de setor censitário.

Para tal, na primeira sessão deste trabalho, discutimos a noção da favela como fractal. Neste sentido, as favelas possuiriam uma estrutura socioespacial que reproduz a estrutura da cidade como um todo, ao mesmo tempo em que está articulada a ela.

Na segunda sessão, apresentamos os matérias e métodos utilizados para quantificar a estratificação socioespacial em três favelas do Rio de Janeiro, o Complexo do Alemão (CA), a Rocinha (RO) e a Fazenda Coqueiro (FC). Verificamos a hipótese de que há significativas desigualdades socioespaciais internas às favelas (ou aos bairros quase inteiramente compostos por aglomerados subnormais ${ }^{3}$ ).

Nas considerações finais, reforçamos que, assim como na cidade, os setores censitários de mais alta renda concentram melhor infraestrutura, maior escolaridade, maior número de pessoas de cor branca, etc - indicando uma reprodução da desigualdade da escala da cidade para as favelas.

\section{Favelas como fractal}

Diversas pesquisas discutem a visão hegemônica nos estudos urbanos da representação dual das cidades (centro/periferia; urbano/ suburbano). Soja (2013) argumenta que a forma metropolitana de urbanização foi dominante por muito tempo e fez com que o "dualismo urbano-suburbano" se colocasse como a única forma de urbanização.

A literatura sobre estudos urbanos reflete diretamente esta divisão dicotômica dos mundos urbanos. Este dualismo urbano-suburbano foi tão tenaz em sua influência sobre o nosso modo de pensar a cidade que, mesmo quando suas características essenciais começaram a desaparecer, como foi o caso nestes últimos trinta anos, as mudanças continuam despercebidas ou são então reabsorvidas dentro das mesmas velhas características dualistas. É

3 É o conjunto constituído por 51 ou mais unidades habitacionais caracterizadas por ausência de título de propriedade e pelo menos uma das características abaixo: Irregularidade das vias de circulação e do tamanho e forma dos lotes e/ou carência de serviços públicos essenciais (como coleta de lixo, rede de esgoto, rede de água, energia elétrica e iluminação pública) (IBGE, 2010b). 
interessante notar que algo muito semelhante ocorreu há um século, quando o modelo metropolitano emergiu de uma cidade muito mais centralizada, como era a cidade industrial capitalista do século XIX (Soja, 2013, p. 152).

Para o autor, a partir dos anos 1960 ocorreram transformações na estrutura urbana, relacionadas à formação de uma "nova e flexível economia pós-fordista" (p.144). Assim, cunha o termo postmetropolis para se referir "aos aspectos da mudança urbana que foram identificados e às literaturas específicas e espacialmente ricas (discursos) que emergiram do esforço de dar sentido prático e teórico a essas mudanças". (p.143).

Nesta passagem, Soja (2000, p.283) argumenta que há uma maior complexidade no esquema dualista de estruturação urbana das cidades pós-1960. Ele defende que há uma reestruturação do mosaico social na postmetropolis, o que denomina "cidade fractal".

Muito amplamente definido, um fractal é qualquer coisa que contenha em suas partes imagens auto-similares do todo. Um exemplo comum são os vasos sanguíneos em sua mão, que se assemelham ao sistema circulatório do corpo inteiro. Essa foi uma característica importante, sugerindo que cada peça do mosaico socioespacial reestruturado pode ser vista como uma espécie de hieróglifo social que representa e revela toda a dinâmica complexa da transição pós-metropolitana ${ }^{4}$.

A ideia de Soja (id.), de uma estrutura fractal que se auto repete dentro de si mesma em diferentes escalas, pode ser melhor compreendida no esquema da Figura 1. Esta ideia é importante para a nossa análise, já que estamos trabalhando com uma reprodução da estrutura socioespacial das cidades nas favelas.

FIGURA 1: Ilustração de uma estrutura fractal

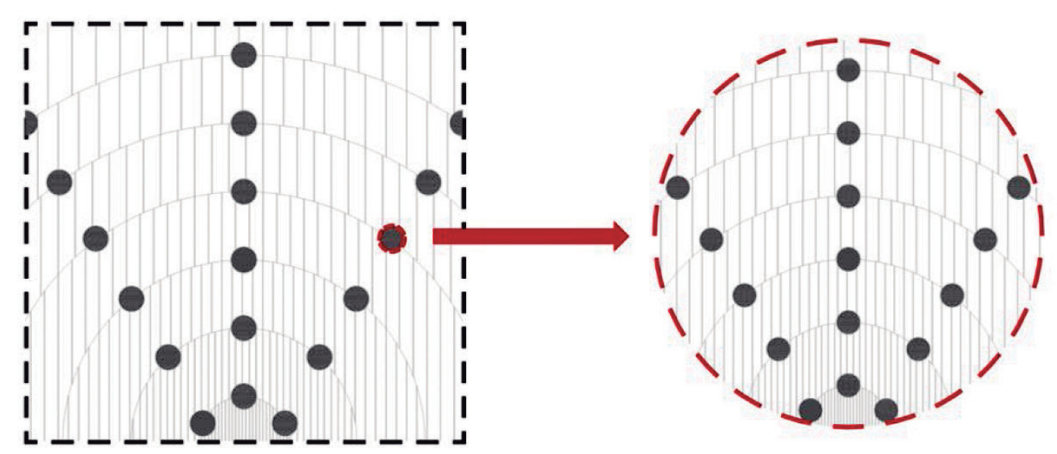

Fonte: Elaboração Própria

Batty e Longley (1994, p.23 - tradução nossa ${ }^{5}$ ), argumentam que as abordagens sobre a estrutura das cidades mudaram muito desde os anos 1960, com isso o que "é amplamente aceito, talvez com um pouco de relutância por alguns, é que as cidades são espelhos e microcosmos da sociedade e da cultura em geral".

$4 \quad$ Do original: "Very broadly defined, a fractal is anything that contains in its parts selfsimilar images of the whole. One common example is the blood vessels in your hand, which resemble the entire circulatory system of the body. This was an appealing quality, suggesting that each piece of the restructured sociospatial mosaic can be seen as a kind of social hieroglyph representing and revealing all the complex dynamics of the postmetropolitan transition."

5 Do original: "is widely accepted, perhaps a little reluctantly by some, is that cities are mirrors and microcosms of society and culture at large." 
Em uma perspectiva antropológica, Elias e Scotson (2000) no trabalho sobre Winston Parva descrevem que os conflitos e relações de dominação presentes em outras escalas se reproduziam naquela comunidade. Seria então uma miniatura de um tema humano universal.

Pareceu útil permitir que o microcosmo de uma pequena comunidade esclarecesse o macrocosmo da sociedade em larga escala e vice-versa. É essa linha de raciocínio que está por trás do emprego de um pequeno cenário como paradigma empírico de relações estabelecidos-outsiders que, muitas vezes, existem em outros lugares em escala diferente (Elias \& Scotson, 2000, p. 49).

Portanto, pensar as cidades ou pequenas comunidades como fractais de uma estrutura mais ampla é fundamental. A teoria dos fractais, que teve origem na matemática, determina que uma estrutura esteja, ao mesmo tempo, articulada e no interior de uma estrutura maior, reproduzindo-a. Estas estruturas são observadas em diferentes escalas.

Na nossa pesquisa, ainda que não seja possível falar em uma total correspondência entre as duas escalas de análise - a da cidade e da favela - podemos pensar que a favela possui uma estrutura própria, mas ao mesmo tempo faz parte de uma estrutura maior, a cidade, como na teoria dos fractais.

Estas estruturas mudam de acordo com a escala que são percebidas, inclusive em determinada escala pode haver um processo de homogeneização de estruturas menores (Ver Figura 2). A questão da escala é relevante para qualquer discussão acerca do espaço, seja ele urbano, regional, nacional ou global. A escala deve ser percebida como um instrumento metodológico de análise do espaço, pois determinados fenômenos são evidenciados ou obscurecidos de acordo com a perspectiva de observação definida, ou seja, depende da escala a ser definida.

FIGURA 2: Ilustração da mudança de escala

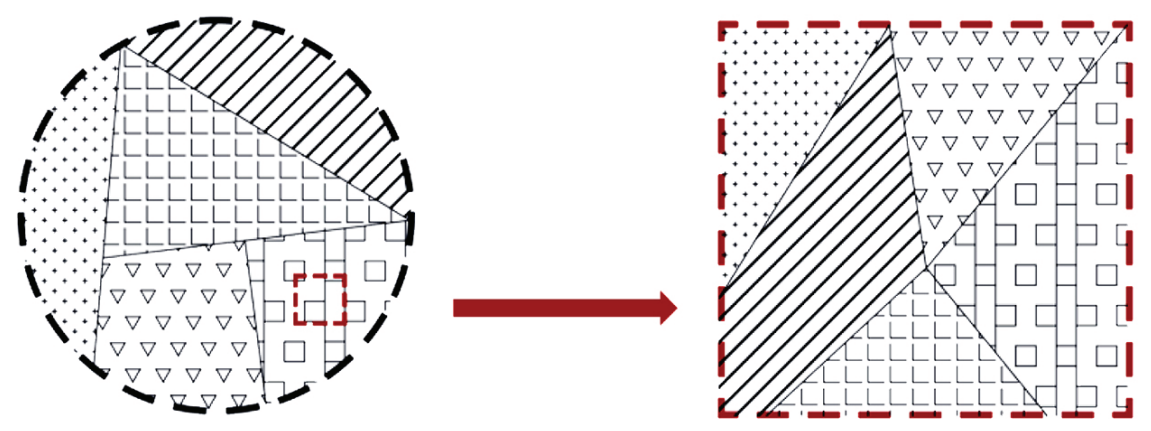

Fonte: Elaboração Própria

Castro (2012) complementa a reflexão apontando que "quando o tamanho muda, as coisas mudam". Logo, dependendo da escala que se escolhe utilizar serão priorizados alguns fenômenos em detrimento de outros. Assim, a escala pode mostrar uma área como homogênea ou não. Com efeito, "homogeneidade e heterogeneidade resultam da perspectiva de observação, fruto de uma escolha, que deve ser consciente e explicitada" (Castro, 2012). A escala geográfica é ainda

(...) a escolha de uma forma de dividir o espaço, definindo uma realidade percebida/concebida, é uma forma de dar-lhe uma figuração, uma representação, um ponto de vista que modifica a percepção mesma da natureza deste espaço, e finalmente, um conjunto de representações coerentes e lógicas que substituem o espaço observado (ibid. p.136). 
Podemos associar, portanto, que o próprio conceito da favela enquanto espaço de pobreza está vinculado a uma escala de observação. Se nossas análises se concentrarem numa maior proximidade, em termos escalares, como as favelas, perceberemos que ela não é tão somente o lugar da pobreza, como percebido pelo senso comum.

Portanto, nos debruçamos sobre a estrutura socioespacial das favelas, assumindo que a maioria dos modelos até hoje elaborados partiam da escala da cidade para as suas proposições. Nós partiremos da escala dos bairros/favelas, para compreender seus processos de desigualdade e diferenciação que muitas vezes não são vistos na escala (cidade) predominante nos estudos urbanos.

\section{Materiais e métodos}

\section{1 Áreas de Estudo}

Trabalhamos com três áreas ${ }^{6}$ localizadas em regiões distintas da cidade do Rio de Janeiro: Complexo do Alemão ("Zona Norte") e Rocinha ("Zona Sul”) e Fazenda Coqueiro ("Zona Oeste"). A delimitação das áreas estudadas foi feita a partir do limite dos bairros oficiais (grande parte do bairro é considerado aglomerado subnormal) para Rocinha (RO) e Complexo do Alemão (CA). Para o Complexo da Fazenda Coqueiro (FC), utilizamos o limite de aglomerados subnormais delimitado pelo IBGE, já que a FC se localiza dentro do bairro de Senador Camará.

Ao analisar essas diferentes localizações intra-urbanas, nossa intenção é detectar a influência da posição geográfica de cada favela sobre a sua estrutura socioespacial. $\mathrm{Na}$ estrutura da cidade do Rio de Janeiro, a chamada "Zona Sul", abrangendo a orla atlântica mais próxima do centro, foi palco de intensa valorização imobiliária ao longo do século XX, atraindo a população mais abastada da cidade ${ }^{7}$.

A ocupação na chamada "Zona Norte" teve relação direta com a industrialização na cidade, já que a partir de 1930 as indústrias migraram para o subúrbio, ocupando a faixa lindeira aos trilhos. Em 1937 o Estado definiu pela primeira vez a zona industrial na cidade. O Decreto 6.000/37 excluía os bairros que tinham uma tradição fabril (Gávea, Jardim Botânico e Laranjeiras na Zona Sul) e incluía grande parte da Zona Norte, além da faixa ferroviária que levava à Central do Brasil (Abreu, 2011).

A atração de mão-de-obra de outros estados intensificou o crescimento do subúrbio carioca a partir dos anos 1930. Foi ocupada por população mais pobre que utilizava o transporte ferroviário para se locomover aos seus locais de trabalho, no centro e imediações (ABREU, 2011). Em 1946, com a inauguração da Avenida Brasil e a destinação das imediações para as atividades industriais, houve um aumento significativo da favelização na cidade. Diferentemente da Zona Sul, a Zona Norte tem uma carência de diversos serviços e infraestrutura, principalmente nos bairros mais pobres.

A Zona Oeste foi considerada a Zona Rural da cidade do Rio de Janeiro até meados do século XX. A intensificação da ocupação começou nesta região na década de 1970, com a criação do bairro Barra da Tijuca, área prevista para a expansão da Zona Sul da cidade. Os demais bairros da região foram se desenvolvendo neste período, com a concentração

\footnotetext{
6 Inicialmente pensamos em trabalhar com o limite das favelas, chamado de "aglomerados subnormais" pelo IBGE. No entanto, as áreas escolhidas foram reconhecidas como bairro no final da década de 1990, assim sendo, preferimos trabalhar com o limite do bairro, no qual a maior parte é favela, para fazer uma análise mais completa das suas estruturas.

$7 \quad$ Em termos de conteúdo social, a Zona Sul, no entanto, precisaria incorporar a Barra da Tijuca, bairro litorâneo mais afastado do centro.
} 
da população de classe média baixa. O bairro de Campo Grande é tido como um subcentro da cidade, concentrando diversos serviços especializados para pessoas que vivem na região (Silva \& Gamarski, 2010).

Na última década a dinâmica populacional mostra que a Zona Oeste cresceu $150 \%$ enquanto a Zona Sul perdeu moradores. Segundo a Associação de Dirigentes de Empresas do Mercado Imobiliário (ADEMI) " $68,5 \%$ de todas as unidades habitacionais lançadas na cidade entre 2005 e 2010 estavam concentradas em quatro bairros da zona oeste: Barra da Tijuca, Jacarepaguá, Recreio e Campo Grande ${ }^{8 "}$.

Cabe ainda acrescentar o papel da política habitacional empreendida pelo governo federal associado aos governos locais, o PMCMV, que concentrou a população de classe média baixa e classe baixa nas áreas periféricas da cidade (Faulhaber \& Azevedo 2015).

Posto isto, podemos perceber hoje, grosso modo, a Zona Sul como a área de mais alta renda na cidade e concentrando melhor infraestrutura urbana, equipamentos e serviços; a Zona Norte destinada à classe-média e média baixa e a Zona Oeste pode ser compreendida como uma área em expansão, e voltada também para uma população de renda mais baixa.

Trabalhar com três agrupamentos de favelas, localizados nestas três áreas distintas da cidade, se justifica na medida em que pretendemos verificar efeitos de localização. Isto é, compreender se a posição geográfica influencia na estrutura socioespacial de cada agrupamento.

\subsection{Dados}

Os dados utilizados são provenientes do Censo fornecido pelo IBGE para o ano de 2010 ao nível do setor censitário. Cabe destacar que cada bairro tem em média 60 setores censitários. Setor censitário é uma área delimitada pelo IBGE com aproximadamente 300 domicílios e que pode ser coberta por um único recenseador (IBGE, 2010a).

Obter os dados neste nível de agregação foi o que nos permitiu estudar as diferenciações nos agrupamentos de favelas. Ou seja, se os dados fossem fornecidos em um nível de agregação maior, perceber as diferenciações se tornaria uma tarefa difícil, podendo inclusive comprometer os resultados. Da mesma maneira, se a pesquisa tivesse sido feita utilizando os microdados poderíamos ter obtido um retrato mais fino das disparidades.

Utilizamos variáveis referentes ao rendimento médio mensal, infraestrutura (abastecimento de água, energia, esgotamento sanitário e coleta de lixo pelo serviço de limpeza), proporção de dependentes e pessoas idosas, proporção de pessoas brancas, proporção de alfabetizados e densidade domiciliar (número de pessoas por domicílio) - fornecidos pelo IBGE.

\subsection{Método}

Nosso método consistiu, em primeiro lugar, na análise espacial com a espacialização dos agrupamentos de renda utilizando o software TerraView, através do índice de Moran Local. Assim, a partir do "Valor do rendimento nominal médio mensal das pessoas responsáveis por domicílios particulares permanentes (com e sem rendimento)", levantada pelo IBGE no Censo 2010 calculamos o Índice de Moran Local. Este índice permite identificar agrupamentos (clusters) de setores censitários para os quais o comportamento da variável mencionada é sensível à vizinhança. Este procedimento regionaliza o conjunto de setores,

8 Bairros na Zona Oeste do Rio crescem até 150\% em uma década, diz IBGE. O Globo. Rio de Janeiro, 01 jul. 2011. Disponível em <http://g1.globo.com/brasil/noticia/2011/07/ibge-bairros-na-zona-oeste-do-riocrescemate-150.html> Acesso em 01 nov. 2016. 
identificando (1) agrupamentos de setores com altos valores da variável, (2) agrupamentos de setores com baixos valores da variável, (3) agrupamento de setores com altos valores "intrusos" e (4) agrupamentos de setores com baixos valores "intrusos".

A partir disso, analisamos a estrutura socioespacial dos agrupamentos de mais alta (1) e de mais baixa renda (2) de acordo com os valores médios de variáveis como densidade domiciliar, infraestrutura, proporção de idosos, proporção de dependentes, proporção de brancos e proporção de alfabetizados. Este método foi aplicado em duas escalas, concebidas aqui como níveis de abrangência dos dados: município e bairro/favela. Esta última análise foi adaptada da metodologia do trabalho de Oakley e Logan (2007). Na sua metodologia original eles utilizaram o Índice de Moran Local para compreender a diferenciação entre os clusters de alta e baixa renda na cidade de Nova lorque. A partir disso, estavam interessados em compreender a quantidade e qualidade de serviços e equipamentos públicos existentes nos dois agrupamentos.

\section{Resultados e discussão}

\subsection{A Cidade do Rio de Janeiro}

Ao aplicar o Índice de Moran sobre a variável de renda para a escala do município, no ano de 2010, fica evidente a polarização norte/sul; baixa/alta renda na cidade. Como pode ser observado na (Figura 3), o agrupamento de mais alta renda é representado pela cor azul escuro (zona sul da cidade) e o agrupamento de baixa renda é representado pela cor vermelha (zonas norte e oeste). Nas cores azul claro e rosa são representadas as zonas de transição do alto para o baixo e do baixo para o alto, respectivamente.

No que se refere à renda, o grupo de mais alta renda possui resultados cinco vezes maior que o grupo de mais baixa renda. A proporção de idosos e dependentes também é um indicador importante para esta análise. A proporção de idosos com idade igual ou superior a setenta anos é mais do que o dobro na região de alta renda. Esta variável tem relação direta com a qualidade de vida, já que sugere que, nas áreas mais ricas, as pessoas têm uma expectativa de vida maior. A proporção de dependentes, com idade menor ou igual a catorze anos, também é cerca do dobro na região de baixa renda, o que pode indicar piores condições de vida, já que a renda per capita tende a ser menor. A densidade domiciliar, calculada como a média de moradores por domicílio, também demonstra que os domicílios do agrupamento de baixa renda são mais densos. A proporção de brancos também é praticamente o dobro no agrupamento de alta renda. Esta análise corrobora a relação entre segregação racial e desigualdade de renda. Da mesma forma, a proporção de alfabetizados, com idade maior ou igual a cinco anos, é maior na área de alta renda, mas há uma discrepância relativamente pequena na comparação com o agrupamento de baixa renda.

Com relação às variáveis de infraestrutura - água, esgoto, energia e lixo - a diferença é mais visível com relação as variáveis médias de esgoto e lixo. A proporção de domicílios ligados à rede geral de esgoto é cerca de $86.7 \%$ no agrupamento de baixa renda e de $96.6 \%$ no agrupamento de alta renda. Enquanto a proporção de domicílios atendidos pelo serviço de coleta de lixo é de $86,7 \%$, no agrupamento de baixa renda, a proporção é $96.6 \%$ no agrupamento de alta renda.

Cabe destacar, ainda, que na escala da cidade, as favelas se comportam como bolsões de pobreza. Os dados analisados neste nível de agregação mostram as três áreas estudadas como homogeneamente pobres - situação que é modificada quando analisamos os dados no nível de abrangência da favela/ bairro. 


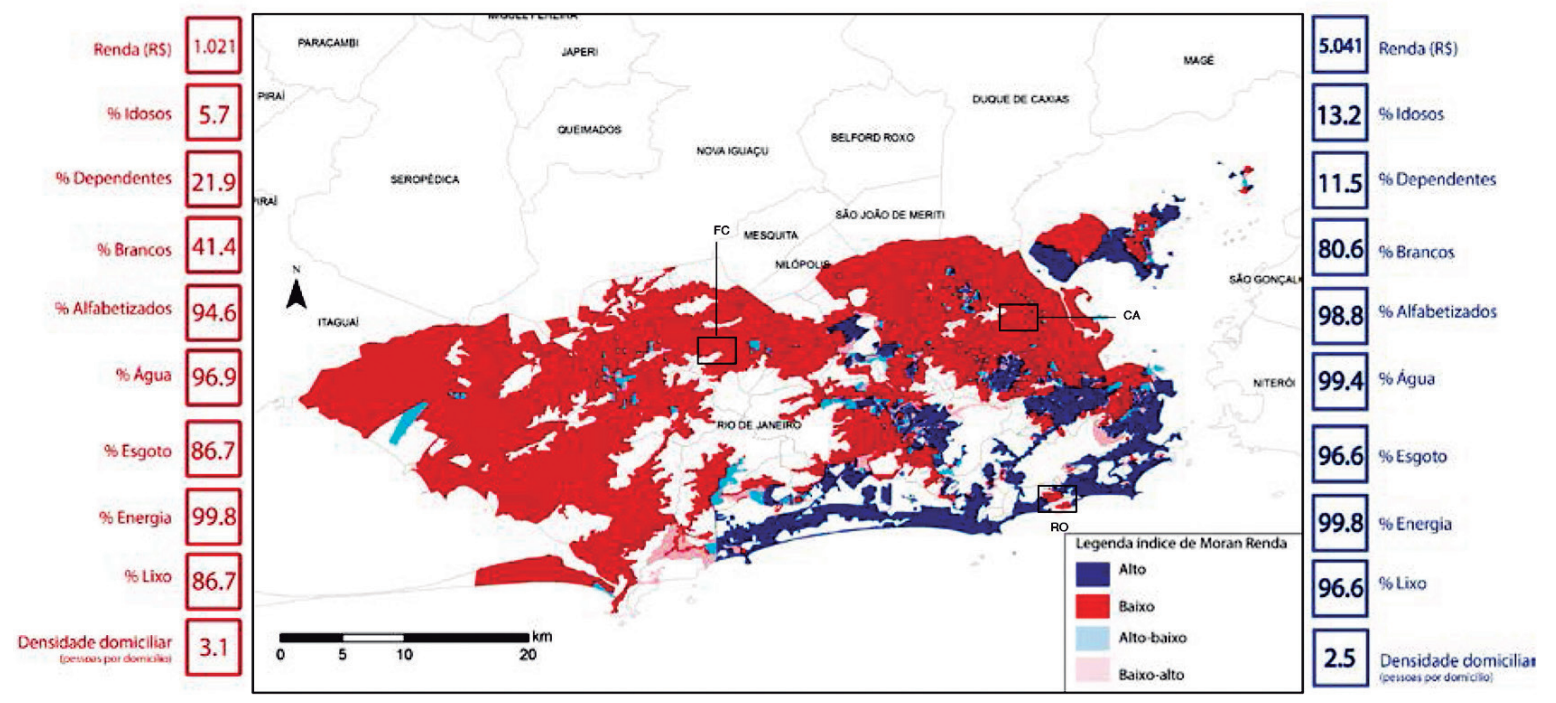

Fonte: Elaboração própria com base no Censo IBGE 2010

\subsection{Complexo do Alemão}

A mesma análise foi realizada para o Complexo do Alemão, utilizamos os mesmos dados anteriores, como pode ser visto na Figura 4. A primeira percepção desta análise é que há no Complexo do Alemão uma separação em dois grupos de renda, assim como na cidade do Rio de Janeiro, ou seja, em vermelho, o grupo de mais baixa renda e em azul, o grupo de mais alta renda. O grupo de renda mais baixa localiza-se na área que possui topografia mais acidentada próxima à Serra da Misericórdia. Enquanto o grupo de maior renda coincide com a parte baixa do bairro.

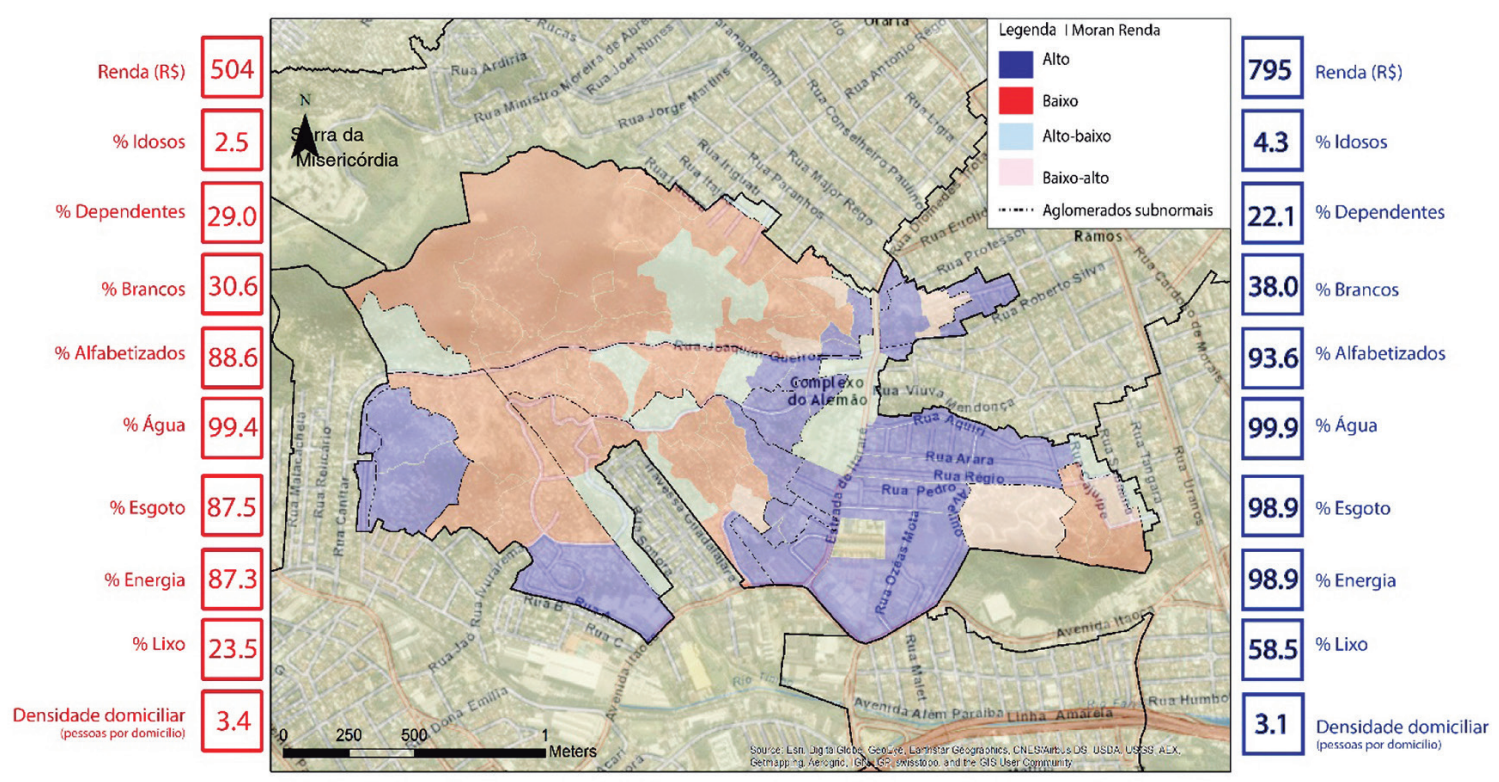

Fonte: Elaboração própria com base no Censo IBGE 2010

Além disso, é possível perceber que a disparidade de renda entre a média do agrupamento de alta e a média do agrupamento de baixa é 1,6 vezes. A maior densidade domiciliar, característica dos domicílios mais pobres da cidade, foi verificada também no agrupamento de menor renda do Complexo do Alemão, apesar de não haver uma 
discrepância muito grande entre os agrupamentos. A infraestrutura tem uma nítida relação com a renda, especialmente as variáveis esgoto, energia e lixo, visto que há uma maior proporção de domicílios com acesso a esses serviços na área de alta renda.

A proporção de idosos no agrupamento de alta renda é quase em relação ao agrupamento de baixa renda. O número de dependentes é mais expressivo no agrupamento de baixa renda do que no de alta renda, apresentando uma diferença $29 \%$ para $22,1 \%$.

A proporção de brancos também é uma variável importante, já que há uma segregação racial na cidade que concentra os brancos nas áreas de mais alta renda. Para o Complexo do Alemão o mesmo fenômeno foi observado, enquanto no agrupamento de baixa renda há $30,5 \%$ de brancos, no agrupamento de alta renda a proporção é de $38 \%$.

Por fim, a taxa de alfabetizados completa o panorama de análise, mostrando que enquanto no agrupamento de alta renda $93,6 \%$ dos residentes são alfabetizados, no agrupamento de baixa renda, apenas $88,6 \%$ são alfabetizados.

\section{3 Rocinha}

Para a Rocinha, observamos que em quase todas as dimensões analisadas, a discrepância entre os agrupamentos é menor do que no Complexo do Alemão. Apesar disso, nossa hipótese também se confirma para a Rocinha, como pode ser visto na Figura 5. É possível perceber a diferenciação entre grupos de renda. No agrupamento de casas que fica acima do Túnel Zuzu Angel está o cluster de renda mais baixa, enquanto a parte mais baixa que tem acesso pela Estrada da Gávea conta com um grupo de domicílios que possui a renda mais alta.

FIGURA 5: Rocinha - RJ
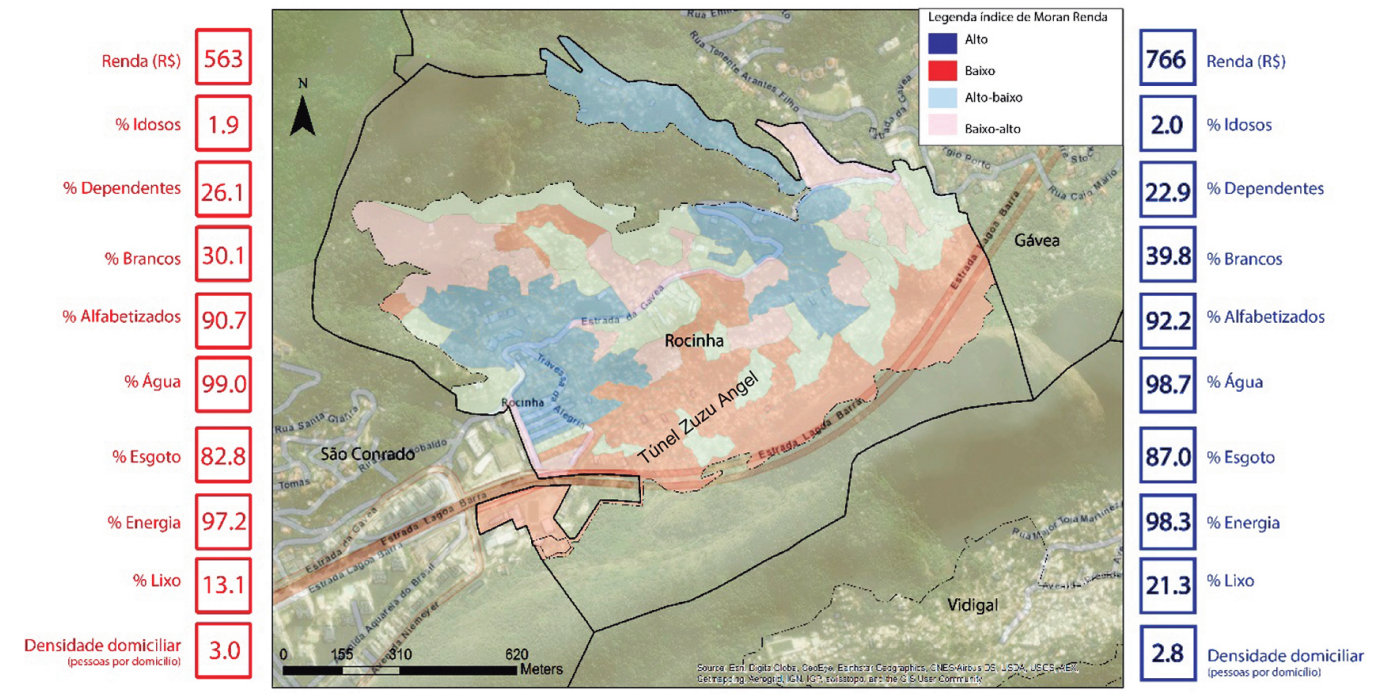

Fonte: Elaboração própria com base no Censo IBGE 2010

No que se refere à renda, o agrupamento de renda mais alta é em média cerca de 1,4 vezes maior do que o agrupamento de mais baixa renda. A densidade domiciliar tem uma variação pouco significativa entre os agrupamentos. A infraestrutura também é melhor no agrupamento de alta renda, com destaque para a proporção de esgoto, com $87.0 \%$ para a alta renda, contra $82.6 \%$ para a baixa renda; e lixo, que se apresenta baixa nos dois clusters, mas ainda é significativamente maior no de alta renda. A proporção de idosos é praticamente a mesma nos dois agrupamentos e o número de dependentes também varia pouco, mas ainda é maior no agrupamento de baixa renda - a exemplo do que vimos no CA. Quanto à proporção de alfabetizados, a disparidade entre clusters também não é muito significativa. 
A proporção de brancos é a variável mais significativa do ponto de vista da discrepância entre os dois agrupamentos. No agrupamento de alta renda há quase $40 \%$ de brancos, para $30,1 \%$ no agrupamento de baixa renda.

\section{4 Fazenda Coqueiro}

Para o ano de 2010, utilizando o limite dos "aglomerados subnormais" fornecidos pelo IBGE, foi possível perceber uma polarização leste/oeste, como pode ser visto na Figura 6. As demais análises seguiram a tendência das outras áreas estudadas. A discrepância de renda entre os dois grupos é cerca de 1,4 vezes maior no grupo de mais alta renda.

A proporção de pessoas idosas aumentou nos dois grupos de renda em relação ao período anterior. Mas, ainda assim, o grupo de maior renda continuou com uma proporção maior de pessoas idosas. Assim como a proporção de dependentes que caiu nos dois clusters, mas continuou maior no grupo de menor renda. A proporção de pessoas brancas também foi maior no grupo de mais alta renda, ainda que a discrepância entre os grupos seja pequena, de $2,3 \%$.

Quanto à infraestrutura, vemos que não há grandes problemas quanto ao abastecimento de água e a energia elétrica nos dois grupos de renda. Mas os dados de esgotamento sanitário e coleta de lixo demonstram que o grupo de menor renda tem condições mais precárias. Por fim, a densidade domiciliar é maior no agrupamento de menor renda - a exemplo do observado nas outras áreas estudadas.

Figura 6: Complexo da Fazenda Coqueiro - RJ

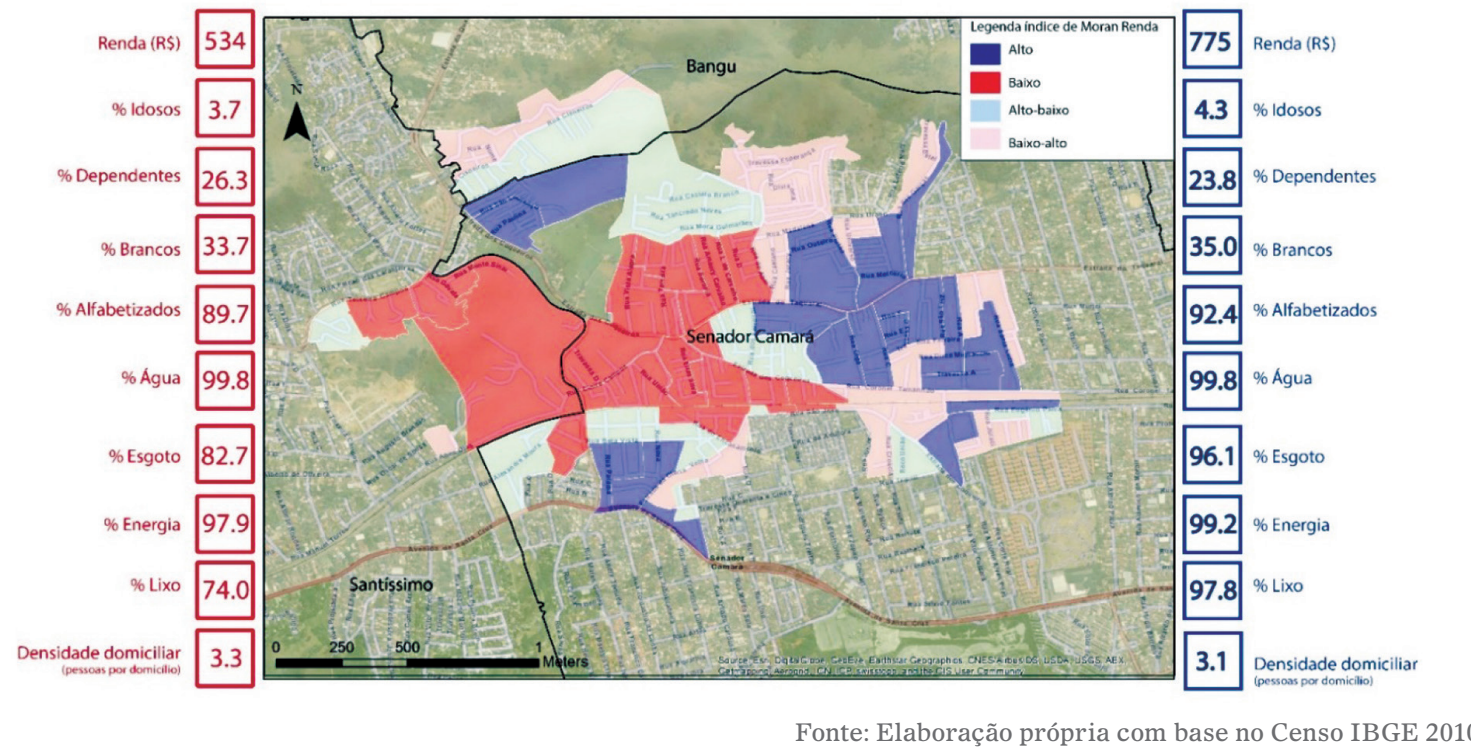

\section{Considerações finais}

A partir da análise apresentada na sessão anterior, podemos concluir que a desigualdade da cidade é, de certa forma, reproduzida nas favelas. Em todas as favelas estudadas, as piores condições socioeconômicas e de infraestrutura coincidem com áreas onde vive a população de menor renda.

A visão homogeneizante sobre as favelas, muitas vezes, faz com que o discurso publicitário do Estado sobre as suas intervenções ganhe força e seja encarado como uma forma de combater a pobreza. Intervir, seja na forma de infraestrutura urbana ou na construção 
de equipamentos, em áreas nas favelas que já possuem uma intervenção prévia e que têm relativamente melhores condições de infraestrutura é reproduzir a desigualdade já existente nestas áreas e não combater a pobreza.

Quanto aos possíveis efeitos de localização, de forma geral, o Complexo do Alemão parece ser a área mais precária com relação às variáveis de renda e infraestrutura. A Rocinha e a Fazenda Coqueiro apresentam dados equivalentes para muitas das variáveis consideradas. Isto nos permite verificar que, apesar de estar localizada na Zona Sul da cidade, em meio a uma região de renda alta, a Rocinha não aufere "benefícios" por esta localização. Também não podemos atribuir à localização as condições verificadas, no caso tanto do Complexo da Fazenda Coqueiro e do Complexo do Alemão; o Complexo do Alemão apresenta resultados piores em vários aspectos quando comparado aos da Fazenda Coqueiro.

Quanto à estrutura espacial, observamos que as áreas mais pobres estão localizadas nas regiões mais acidentadas e de difícil acesso. No caso do Complexo do Alemão, o grupo de menor renda se localiza próximo à Serra da Misericórdia, enquanto, na Rocinha, os domicílios mais pobres localizam-se em cima do Túnel Zuzu Angel. Além disso, as áreas de renda mais alta hoje coincidem com as áreas de ocupação mais antiga, como a porção leste do CA, a parte mais baixa da RO e a porção Sul da FC - onde as habitações são mais consolidadas.

Por fim, nossa investigação buscou mostrar que as desigualdades da cidade se reproduzem nas favelas. A nossa hipótese de que a estrutura socioespacial que separa ricos e pobres também ocorre nas favelas pode ser verificada, sobretudo, no Complexo do Alemão, que apresentou uma discrepância maior entre os grupos de renda. No Rio de Janeiro, esta estrutura compreende a separação entre grupos de renda, na qual o grupo com maior renda tem mais acesso a melhores equipamentos, serviços, infraestrutura urbana, maior expectativa de vida, maioria da população de cor branca, mais alta escolaridade, entre outros aspectos. Como vimos, este padrão se reproduz nas favelas, ainda que com uma discrepância muito menor entre os grupos, já que a escala espacial é muito menor. Essa diferenciação está fortemente associada ao tamanho geográfico do objeto. No entanto, cabe enfatizar que esta desigualdade entre os agrupamentos é significativa para esta escala, corroborando a necessidade de reconhecer a microgeografia da favela para pensar as políticas públicas.

Nossa contribuição para os estudos da estrutura socioespacial das favelas foi através do uso de métodos quantitativos. Com os dados do Censo do IBGE para o ano de 2010, mostramos que a estrutura socioespacial das favelas é mais complexa do que se poderia supor ao ser analisada na escala da cidade, subsidiando a desconstrução do estigma da favela como um lugar homogêneo de pobreza. 


\section{Referências bibliográficas}

ABREU, M. Evolução Urbana do Rio de Janeiro. $4^{\text {a }}$ ed. Rio de Janeiro: Instituto Pereira Passos, 2006.

ALVITO, M. As Cores de Acari: Uma Favela Carioca. Rio de Janeiro: FGV, 2001.

BATTY, M. LONGLEY, P. Fractal Cities: A geometry of form and function. San Diego: Academic Press, 1994.

CARVALHO, C. Cidades dentro da Cidade? A Estrutura Socioespacial de Favelas Cariocas no Período Lula (2003-2010). 2016. 148f. Dissertação. (Mestrado em Planejamento Urbano e Regional). Universidade Federal do Rio de Janeiro: Rio de Janeiro, 2016.

CASTRO, I. "O problema da escala". In CASTRO, Iná Elias; GOMES, Paulo Cesar da Costa; CORREA, Roberto Lobato. (orgs.) In: Geografia: Conceitos e Temas. Rio de Janeiro: Bertrand Brasil, 2012.

ELIAS, N. Scotson, J. Os estabelecidos e os outsiders. Rio de Janeiro: Jorge Zahar, 2000. FAULHABER, L. AZEVEDO, L. SMH 2016: Remoções no Rio de Janeiro Olímpico. Rio de Janeiro: Mórula, 2015.

IBGE. Instituto Brasileiro de Geografia e Estatística, Censo Demográfico 2010. Rio de Janeiro, 2010a.

IBGE, Instituto Brasileiro de Geografia e Estatística. Censo demográfico: 2010: aglomerados subnormais: informações territoriais. Rio de Janeiro, $2010 \mathrm{~b}$.

MACHADO DA SILVA, L. A. A Política na favela. In: DILEMAS: Revista de Estudos de Conflito e Controle Social - Vol. 4 - no 4 - out/nov/dez 2011 - pp. 699-716.

MORRIS, F. A geografia social no Rio de Janeiro. In: Revista Brasileira de Geografia. Rio de Janeiro: V. 35, n. 1, 1973, p. 3 - 75, jan./mar.

NUNES, J. Apontamentos sobre a Maré: Uma Compreensão. In: Revista Brasileira de Estudos Urbanos e Regionais. Rio de Janeiro: v.9, n.1, 2007, p. 53 - 68.

OAKLEY, D. LOGAN, J. A Spatial Analysis of the Urban Landscape: What Accounts Differences across Neighborhoods? In: LOBAO, L. HOOKS, G. TICKAMYER, A. (orgs.). The Sociology of Spatial Inequality. New York: State University of New York, 2007.

PRETECEILLE, E. VALLADARES, L. Favela, Favelas: unidade ou diversidade da favela carioca. In: RIBEIRO, L. C. (Org.). O Futuro das Metrópoles: desigualdades e governabilidade. Rio de Janeiro: REVAN/FASE, 2000.

SILVA, J. As Unidades Policiais Pacificadoras e os novos desafios para as favelas cariocas. In: MELLO, M. MACHADO DA SILVA, L. A. FREIRE, L. SIMÕES, S. (orgs.). Favelas cariocas: ontem e hoje. Rio de Janeiro: Garamond, 2012.

SILVA, J. P. GAMARSKI, E. Campo Grande: Algumas Considerações sobre seu Desenvolvimento. In: Encontro Nacional de Geógrafos, 15, Porto Alegre. Anais... Porto Alegre, 2010.

SOJA, E. Postmetropolis. Critical Studies of cities and regions. Oxford, Blackwell, 2000. Para Além de Postmetropolis. In: Revista UFMG, Belo Horizonte, v.20, 2013, n.1, p. 136-167, jan/jun.

VALLADARES, L. A invenção da favela: do mito de origem a favela.com. Rio de Janeiro: FGV, 2005. 